\title{
El porvenir de Jacques Derrida
}

\author{
Jacques Derrida's 'à-venir'
}

\author{
SEBASTIÁN CHUN \\ UBA - CONICET (Argentina)
}

Recibido: 04-05-2011

Aprobado definitivamente: 11-05-2011

\section{RESUMEN}

El porvenir de Jacques Derrida se juega en su reflexión sobre lo político, la cual gira a su vez sobre este mismo concepto: porvenir. Por lo tanto, pensar en la deconstrucción de lo político llevada a cabo por Derrida necesariamente nos conducirá a analizar algunos ejes que atraviesan la cuestión del porvenir: herencia, aporía, mesianicidad sin mesianismo e invención. Nos proponemos en este recorrido destacar la importancia del pensamiento de Derrida dentro del debate político contemporáneo y la herencia que nos ha legado, la cual nos obliga a seguir pensando la deconstrucción y su vínculo con la democracia por venir.

PALABRAS CLAVE

PORVENIR - HERENCIA - APORÍA - MESIANICIDAD SIN MESIANISMO - DEMO-

CRACIA POR VENIR

\begin{abstract}
If there's a future (à-venir) for Derrida's philosophy, it depends on his political analysis, where the concept of «à-venir» has a fundamental role. Then, Derrida's deconstruction of the political issue will take us to analyze some issues related to the à-venir question: inheritance, aporia, messianicity without messianism and invention. In this article we will emphasize the importance of Derrida's philosophy for the contemporary political debate. This inheritance makes us go on thinking about the deconstruction and its connection with the democracy to come.
\end{abstract}

\section{KEYWORDS}

\section{FUTURE - INHERITANCE - APORIA - MESSIANICITY WITHOUT MESSIANISM - DEMOCRACY TO COME}

\footnotetext{
(C) Contrastes. Revista Internacional de Filosofía, vol. XVII (2012), pp. 105-118. ISSN: 1136-4076

Departamento de Filosofía, Universidad de Málaga, Facultad de Filosofía y Letras Campus de Teatinos, E-29071 Málaga (España)
} 
Hay que aguardar para ello a la llegada de un nuevo género de filósofos, de filósofos que tengan gustos e inclinaciones diferentes y opuestos a los tenidos hasta ahora, -filósofos del peligroso «quizá», en todos los sentidos de esta palabra. -Y hablando con toda seriedad: yo veo surgir en el horizonte a esos nuevos filósofos.

Nietzsche, Más allá del bien y del mal

Preguntarnos por el PORVEniR De Derrida nos obliga a recordar lo importancia que supo dar este pensador a los juegos de sentido propuestos por el doble genitivo. Por un lado, entonces, la pregunta remitiría a la cuestión fáctica, es decir, al porvenir de Derrida como pensador dentro del despliegue de esa historia de la filosofía que afortunadamente aún no se detiene. Más allá de la promesa con la que nos encontramos después de su muerte de un inmenso legado de textos por publicar, aquí consideramos que el porvenir del filósofo franco-argelino se jugará en el plano de su reflexión sobre lo político. Y así nos acercamos al otro momento del doble genitivo, ya que interrogarnos por la cuestión del porvenir dentro de los textos derridianos significa adentrarse de lleno en dicha reflexión.

Por otro lado, también podemos invertir los términos de nuestro título y preguntarnos si Derrida es uno de esos filósofos del porvenir que anunciara Nietzsche. ${ }^{1}$ La tesis de nuestro trabajo consistirá precisamente en responder afirmativamente a esta pregunta, al considerar a Derrida como un pensador del eterno retorno. Recordemos que la expresión 'eterno retorno de lo mismo' es paradójica en su misma formulación, ya que si todo es un retornar de configuraciones ya dadas de lo real no habría un momento inaugural de las mismas. Y si no hay un origen entonces no habría tampoco una mismidad que pueda volver, ya que ese primer acontecimiento que se repetirá hasta el infinito nunca sucedería en un presente absoluto. Por lo tanto, el eterno retorno de lo mismo estará siempre atravesado por la diferencia, por lo otro, ya que no hay un algo determinado que pueda volver. Desde aquí, y ya trasladándonos al plano político, podemos pensar en otro tipo de cierre del universo político, ya siempre habitado espectralmente por el otro, y otro tipo de apertura, ser hospitalario con ése que ya está alojado en el ámbito de la mismidad. Si bien las configuraciones del escenario político suelen adoptar la apariencia de homogeneidad y solidez, no son monolitos inmunes a las fisuras que toda instancia de clausura alberga dentro de sí. En este sentido, cuando Derrida acepta este pensamiento, el del peligroso

1 Para la relación entre Nietzsche y Derrida véase M. B. Cragnolini, Derrida, un pensador del resto. Buenos Aires: La cebra, 2007, parte C. 
quizá, reconoce justamente que no hay una mismidad eternamente repetida que clausure toda alteridad. En otros términos, si lo posible es aquello regido por ese mismo que parece volver una y otra vez, sólo lo imposible, desde el cual y hacia el cual abre la deconstrucción, nos permite pensar otro modo de ser, más allá de la esencia y del imperio de la razón calculadora. El eterno retorno y el otro, ambos se me escapan en la noche profunda del silencio, y ante ellos sólo cabe una hospitalidad incondicional, la justicia infinita, la llamada al porvenir. ${ }^{2}$

\section{HERENCIA Y PORVENIR}

Algún lector poco atento podría preguntarse si cuando Derrida habla de «otra política» o de la «democracia por venir» cae en un deseo de originalidad absoluta, el cual se expresaría en una indiferencia ante la complejidad de la tradición filosófica, a la que criticaría de manera monolítica, y en la pretensión de trascenderla, escapando a aquello que conforma necesariamente a la misma deconstrucción. ${ }^{3}$ Ante esta posible objeción Derrida respondería que siempre hay herencia, aunque ella misma no es única y homogénea. No hay un pasado original que hoy se pueda repetir, que podamos traer a cuento de manera fiel y obsecuente. Hay múltiples herencias, porque cada una de ellas es también una herencia de herencias, y por lo tanto debemos escoger, es decir, inventar la nuestra. Leemos en Espectros de Marx:

Una herencia nunca se re-úne, no es nunca una consigo misma. Su presunta unidad, si existe, sólo puede consistir en la inyunción de reafirmar eligiendo. Es preciso quiere decir es preciso filtrar, cribar, criticar, hay que escoger entre los varios posibles que habitan la misma inyunción. Y habitan contradictoriamente en torno a un secreto. Si la legibilidad de un legado fuera dada, natural, transparente, unívoca, si no apelara y al mismo tiempo desafiara a la interpretación, aquél nunca podría ser heredado. Se estaría afectado por él como por una causa

2 Como indicio de un posible análisis de la obra temprana de Derrida y su relación con la ética y la política, encontramos ya la expresión «por venir» en uno de sus primeros trabajos husserlianos escrito en 1961: "Todo este debate sólo es inteligible en el interior de algo así como la geometría o la matemática, cuya unidad está por venir a partir de lo que se anuncia en su origen [el destacado es de J.D.].» J. Derrida, Introducción a «El origen de la geometría» de Husserl, tr. D. Cohen. Buenos Aires: Manantial, 2000.

3 Desde ya que no tiene sentido hablar de «originalidad absoluta», entendida como creación ex-nihilo de determinado sistema filosófico, con relación a la deconstrucción. Derrida sí reconoce que no hay un más allá de la historia de la metafísica. Por lo tanto, la deconstrucción se muestra como «un modo de habitar las estructuras metafísicas para llevarlas hasta su límite: solicitación (en el sentido etimológico de «hacer temblar») que permitirá que dichas estructuras muestren sus «fisuras»)». M. B. Cragnolini, «Derrida: deconstrucción y pensar en las "fisuras"», en Derrida, un pensador del resto, op. cit., p. 21. 
-natural o genética. Se hereda siempre de un secreto -que dice: «Léeme. ¿Serás capaz de ello?». ${ }^{4}$

En otras palabras, si una herencia nos condenara a su imperio, volviéndose un mismo que retornara siempre homogeneizando y neutralizando el paso de la historia, no sería una herencia. Heredar implica la différance, el paso por la distancia que separa a ese instante fundacional del hoy que lo actualiza. Por lo tanto, ese presente originario se muestra atravesado por sus propias herencias y el porvenir, es decir, aquello otro que rompe con su univocidad y resulta inanticipable desde su mismo horizonte. ¿Qué es lo que se hereda? Todo, salvo una herencia. ${ }^{5}$

De este modo, Derrida sostiene que la herencia abre nuestro porvenir a partir del llamado a interpretar y reafirmar ese espectro deconstructivo implícito en toda herencia. El porvenir no es algo que se vaya a presentar efectivamente en algún momento presente, sino aquello que rompe precisamente con la lógica de la presencia. ${ }^{6} \mathrm{Y}$ es por ello que no se trasciende la herencia, ya que ella misma trae consigo su más allá, cuya radicalización es la tarea de la deconstrucción. ${ }^{7}$

El ser de lo que somos es, ante todo, herencia [...] no podemos sino testimoniarlo. Testimoniar sería testimoniar lo que somos en tanto que heredamos de ello, y he ahí el círculo, he ahí la suerte o la finitud, heredamos aquello mismo que nos permite testimoniar de ello. ${ }^{8}$

Si hablamos de política y democracia, debemos estar atentos al pasado de dichos conceptos, pero para así dar lugar a esa democracia por venir que implicaría una interpretación performativa de los mismos, es decir, una «interpretación que transforma aquello mismo que interpreta». ${ }^{9}$ Pero, vale la pena reiterarlo, el porvenir de la democracia ya está allí, marcado a fuego en el derrotero de dicho nombre y el desajuste fundamental que ha signado toda efectivización del mismo. Cualquier puesta en práctica de la democracia como forma de gobierno ya está teñida por la democracia por venir entendida como

4 J. Derrida, Espectros de Marx, tr. J. M. Alarcón y C. de Peretti. Madrid: Trotta, 1995, p. 30 .

5 «No heredamos nada salvo la capacidad de heredar y decir, relacionarnos con una lengua, una ley o «algo» que nos permite heredar y por eso mismo atestiguarlo, al heredar...» J. Derrida y B. Stiegler, Ecografías de la televisión, tr. M. H. Pons. Buenos Aires: Eudeba, 1998, p. 163.

6 Para un análisis de la dimensión temporal del porvenir en la política derridiana véase M. McQuillan, «Introduction: The Day After Tomorrow... or, The Deconstruction of the Future», en M. McQuillan (ed.), The Politics of Deconstruction. London: Pluto, 2007.

7 «La herencia no es nunca algo dado, es una tarea». J. Derrida, Espectros de Marx, op. cit., p. 67.

8 Ibid., p. 68.

9 Ibid., p. 64. 
llamado a la deconstrucción. Cuando Derrida se reconoce como un heredero de Marx, desde el momento en que comprende a la deconstrucción como una radicalización del marxismo, ${ }^{10}$ está entendiendo la herencia en ese sentido y no pretendiendo una más original fidelidad. ${ }^{11}$ En sus palabras:

$\mathrm{Si}$ «desde Marx» nombra un por-venir tanto como un pasado, el pasado de un nombre propio, entonces, lo propio de un nombre propio quedará siempre por venir. Y secreto. [...] Lo que se anuncia «desde Marx» puede sólo prometer o recordar que hay que mantener la unión, en un habla que difiere, difiriendo no lo que afirma, sino difiriendo justamente para afirmar, para afirmar justamente, para poder (poder sin poder) afirmar la venida del acontecimiento, su por-venir mismo. ${ }^{12}$

Ser fieles a la herencia de la deconstrucción implica una forma de vínculo previo a todo lazo común: el del habla/escritura. Pero esta promesa anterior a toda política, cuya verdad radica en el diferimiento y así afirma el porvenir del acontecimiento, tiene una forma, la aporética.

\section{APORÍAS}

Hay en Derrida una relación estrecha entre el porvenir y el acontecimiento, desde el momento en que ambos comparten su irreductibilidad al cálculo a partir de las condiciones actuales. En otras palabras, son su imprevisibilidad, su más allá del horizonte presente, su suspensión de todo saber, los que garantizan su (im)posibilidad. Lo único que está por venir es el acontecimiento, si lo hay, ${ }^{13}$ cuya condición de posibilidad es la transgresión de la mera repetición de lo mismo, su irreductibilidad a la racionalidad instrumental y a la aplicación de un programa, es decir, la fidelidad al llamado de la deconstrucción. Ahora bien, la pregunta que podemos hacernos en este punto es cómo pensar el acontecimiento, cómo volver la razón sobre esto que da a pensar. Derrida responde:

Pero el pensamiento del «quizá» involucra quizá el único pensamiento posible del acontecimiento. De la amistad por venir y de la amistad para el porvenir. Pues para amar la amistad no basta con saber llevar al otro en el duelo, hay que amar

10 Ibid., p. 106.

11 Las críticas que suscitó la lectura derridiana de Marx de parte de los celosos "verdaderos» herederos y la respuesta de Derrida a las mismas pueden encontrarse en M. Sprinker (ed.), Demarcaciones espectrales. En torno a Espectros de Marx, de Jacques Derrida, tr. M. Malo de Molina Bodelón, A. Riesco Sanz y R. Sánchez Cedillo. Madrid: Akal, 2002. También es valioso el trabajo del grupo Decontra sobre la relación entre Marx y Derrida en C. De Peretti (ed.), Espectrografías (desde Marx y Derrida). Madrid: Trotta, 2003.

12 J. Derrida, Espectros de Marx, op. cit., p. 31.

13 «Lo que hay, si es que lo hay, no es necesariamente. Eso quizá no existe ni se presente jamás, y sin embargo lo hay, puede que haya». J. Derrida, Políticas de la amistad, seguido de El oído de Heidegger, tr. P. Peñalver y F. Vidarte. Madrid: Trotta, 1998, p. 58. 
el porvenir. Y no hay categoría más justa para el porvenir que la del «quizá». Tal pensamiento conjuga la amistad, el porvenir y el quizá para abrirse a la venida de lo que viene, es decir, necesariamente bajo el régimen de un posible cuya posibilitación debe triunfar sobre lo imposible. Pues un posible que sería solamente posible (no imposible), un posible seguramente y ciertamente posible, de antemano accesible, sería un mal posible, un posible sin porvenir, un posible ya dejado de lado, cabe decir, afianzado en la vida. Sería un programa o una causalidad, un desarrollo, un desplegarse sin acontecimiento. La posibilitación de ese posible imposible debe permanecer a la vez tan indecidible y en consecuencia tan decisiva como el porvenir mismo. ${ }^{14}$

El pensamiento del quizá entonces piensa aquello que escapa a nuestro pensamiento, es decir, a nuestro lenguaje. Si no podemos dejar de traicionar el porvenir cada vez que hablamos sobre él, esto es porque el porvenir nunca llega, sino que siempre está por venir. Otra política, otra democracia, no pueden renunciar al contenido heredado de esos conceptos. Sin embargo, si no hay una herencia determinada, eso que se hereda es siempre la apertura al acontecimiento, a aquello inesperado que irrumpe de manera novedosa sobre el orden constituido y que quizá, pero sólo quizá, pueda suceder. Y aquí Derrida señala la prueba que debe hacer todo porvenir: la aporía del quizá. Por un lado, el quizá abre un posible absolutamente indeterminado, que permite así el acontecimiento y la decisión. Por el otro, toda decisión interrumpe su condición de posibilidad, el quizá mismo. En otras palabras, la decisión (que siempre es de otro y nunca una puesta en acto de una voluntad soberana) y el surgir del acontecimiento clausuran el horizonte abierto a la llegada de lo otro. ${ }^{15}$ En el preciso instante en que del fondo de indeterminación acontece lo imposible, eso ya queda reducido al ámbito de lo posible. Por lo tanto, la justicia, el don, el perdón, si los hay, siempre serán fugaces, imponiéndonos un deber fundamental, el de deconstruir todas las instancias que se realizan en sus nombres.

Por otro lado, Derrida señala la aporía del acontecimiento, que se superpone a la antes analizada. Según esta segunda aporía, la decisión produce acontecimiento, es decir, siempre es una decisión que se toma sobre un suelo de indecidibilidad absoluta. ${ }^{16}$ Por lo tanto, no hay un sujeto que tome una decisión, si comprendemos por tal al individuo claramente determinado, autoconsciente y capaz de calcular las causas y efectos de su decisión. Sin embargo, Derrida

14 Ibid., p. 46.

15 Ibid., p. 86.

16 En Fuerza de ley Derrida da tres ejemplos de aporías íntimamente ligadas a las aquí expuestas. J. Derrida, Fuerza de ley. El «Fundamento místico de la autoridad», tr. A. Barberá y P. Peñalver Gómez. Madrid: Tecnos, 1997, pp. 52-62. 
señala que la decisión neutraliza a su vez esa indeterminación absoluta, ya que siempre tiene un efecto de subjetividad inherente a ella misma.

Sin duda la subjetividad de un sujeto, ya, no decide nunca sobre nada: su identidad consigo y su permanencia calculable hacen de toda decisión un accidente que deja al sujeto indiferente. Una teoría del sujeto es incapaz de dar cuenta de la menor decisión [...] Pero si nada sucede jamás a un sujeto, nada que merezca el nombre de acontecimiento, el esquema de la decisión tiende regularmente, al menos en su acepción común y hegemónica (la que parece seguir dominando el decisionismo schmittiano, su teoría de la excepción y de la soberanía), a implicar la instancia del sujeto, de un sujeto clásico, libre y voluntario, y así de un sujeto al que nada sucede, ni siquiera el acontecimiento singular del que cree, por ejemplo en situación de excepción, que toma y que guarda la iniciativa. [...] ¿Habría que mostrarse hospitalario para lo imposible mismo, a saber, lo que el buen sentido de toda filosofía no puede sino excluir como la locura o el sin-sentido, a saber, una decisión pasiva, una decisión originariamente afectada? [...] la decisión: ésta debe interrumpir, marca un comienzo absoluto. Significa, pues, lo otro en mí, que decide y desgarra. La decisión pasiva, condición del acontecimiento, es siempre en mí, estructuralmente, otra decisión, una decisión desgarradora como decisión del otro. Del otro absoluto en mí, del otro como lo absoluto que decide de mí en mí. [...] Responsable de mí ante el otro, soy en primer lugar y también responsable del otro ante el otro [...] esta heteronomía no contradice a la autonomía, abre ésta a ella misma, representa el latido de su corazón. Otorga la decisión al don, si lo hay, como don del otro. ${ }^{17}$

El sujeto clásico, libre y voluntario, responde al principio de calculabilidad propio de todo lo presente, lo posible, lo estable, lo idéntico a sí. Por ello, no es posible hablar de una decisión de ese sujeto en tanto ésta es siempre el venir del acontecimiento, lo que irrumpe, lo no-calculable e in-anticipable. Por otro lado, toda decisión tiene un efecto de subjetividad necesario, es decir, no puede ir más allá de ese sujeto al que se le impone desde otro lugar. Entonces, una decisión, si la hay, viene de lo otro en mí, ese otro que decide más allá de mí mismo. Sin embargo, no por esto dejo de ser responsable, infinitamente responsable, de esa decisión del otro. ${ }^{18} \mathrm{Y}$ aquí reside el efecto de subjetividad necesario para pensar en otra política: el sujeto de la democracia por venir sería uno cuya identidad estaría conformada por la respuesta y la responsabilidad ante la decisión del otro.

17 J. Derrida, Políticas de la amistad, seguido de El oído de Heidegger, op. cit., pp. 8687.

18 «Una decisión es inconsciente en suma, por insensato que esto parezca, comporta el inconciente y sigue siendo sin embargo responsable». Ibid., p. 88. 
Lo que finalmente se explicita aquí es el papel que tiene en el pensamiento derridiano en general la aporía como instancia de apertura del acontecimiento. ${ }^{19}$ Para que el porvenir tenga lugar, es necesaria la instancia de indeterminación propia de lo aporético, es decir, de aquello que no nos permite trazar de antemano la senda segura que debe seguir nuestra decisión (lo cual la anularía en cuanto tal). Cuando nos vemos atravesados por dos deberes irrenunciables, lo que Derrida llama double bind, precisamente en ese momento lo otro que rompe con la mera repetición de lo mismo es posible. En Fuerza de ley Derrida sostiene incluso que la justicia sería la experiencia de la aporía, es decir, de aquello de lo que no se puede tener experiencia. La justicia sería entonces la única experiencia posible de lo imposible.

El derecho es el elemento del cálculo, y es justo que haya derecho; la justicia es incalculable, exige que se calcule con lo incalculable; y las experiencias aporéticas son experiencias tan improbables como necesarias de la justicia, es decir, momentos en que la decisión entre lo justo y lo injusto no está jamás asegurada por una regla. ${ }^{20}$

La aporía deja entonces de ser un mero callejón sin salida, y el espacio abierto por lo indecidible se hace transitable. Ya no caemos condenados por la ley aristotélica al abismo del silencio, sino que reconocemos que toda instancia de suspensión del cálculo y la causalidad se vuelve condición de posibilidad de la justicia, el respeto absoluto hacia el otro, es decir, la democracia por venir.

\section{MESIANICIDAD SIN MESIANISMO ${ }^{21}$}

Ahora bien, retomando nuestra hipótesis, podemos anticipar una crítica inmediata a la misma. Según ésta, la democracia por venir en sí misma no tendría un contenido determinado, sería una mera forma, en este caso de-

19 «[...] la aporía es el lugar mismo en el cual ha de encontrarse la fuerza política de la deconstrucción». R. Beardsworth, Derrida y lo político, tr. L. Lassaque. Buenos Aires: Prometeo, 2008, p. 19.

20 J. Derrida, Fuerza de ley. El «Fundamento místico de la autoridad», op. cit., p. 39.

21 En respuesta a la traducción que hace Jameson de todo lo referente a lo «mesiánico» en Derrida por «utopismo», el autor de Espectros de Marx cambia la expresión utilizada allí de «mesiánico sin mesianismo» por «mesianicidad sin mesianismo». De este modo, se aleja de la referencia al mesianismo judío constitutiva del pensamiento de Benjamin y a todo intento de leer en el "sin" una carencia, negatividad o aniquilación, para así afirmar que «la mesianicidad (a la que considero una estructura universal de la experiencia y que no se reduce a ningún mesianismo religioso) es cualquier cosa menos utópica: es, en todo aquí-ahora, la referencia a la llegada del acontecimiento más concreto y más real, es decir, a la alteridad más irreductiblemente heterogénea». J. Derrida, «Marx e hijos», en M. Sprinker (ed.), Demarcaciones espectrales. En torno a Espectros de Marx, de Jacques Derrida, op. cit., p. 289. 
constructiva, que abriría la posibilidad del mal uso de la misma. Si la aporía no delimita un espacio dentro del cual asumir la decisión del otro, siempre es posible que una mala decisión se disfrace de justicia. ${ }^{22}$ Así como Hegel critica al imperativo categórico kantiano por ser una forma vacía que se podría llenar con cualquier contenido, la democracia por venir como modo de lo político en constante (auto)deconstrucción estaría siempre bajo la tentación de caer en la posibilidad del mal.

A esta posible crítica Derrida responde:

[...] Cualquiera que sea la modalidad o el contenido de este deber, de esta necesidad, de esta prescripción o de esta inyunción, de esta prenda, de esta tarea, también, pues, de esta promesa, de esta promesa necesaria, es preciso este «es preciso» y ésta es la ley. Esta indiferencia por el contenido no es indiferencia, no es una actitud de indiferencia, al contrario. Al marcar toda apertura al acontecimiento y al porvenir como tales, condiciona el interés y la no-indiferencia por lo que sea, por todo contenido en general. ${ }^{23}$

La indiferencia por la particularidad del contenido de esa promesa no implica la indiferencia por todo contenido en general. Que la tarea deconstructiva tal como es invocada por la democracia por venir sea una llamada a la (auto) crítica constante de cualquier determinación política no quiere decir que no tenga contenido alguno. La cuestión reside en la incapacidad de vislumbrar dicho contenido desde el horizonte presente, sabiendo que toda palabra lanzada sobre el mismo terminará neutralizando su porvenir. A este porvenir sin un contenido determinado Derrida lo llama la mesianicidad sin mesianismo.

Ya sea la promesa de esto o de aquello, ya sea, o no, cumplida o ya resulte imposible de cumplir, necesariamente hay promesa y, por tanto, historicidad como porvenir. A esto es a lo que concedemos el sobrenombre de lo mesiánico sin mesianismo. ${ }^{24}$

¿Qué es entonces la mesianicidad sin mesianismo? Es esta llamada al porvenir, a la alteridad absoluta, al acontecimiento, pero sin horizonte de espera. No debo anticipar, predecir o condicionar la llegada del otro, en este caso de otra política, ya que así estoy cancelando la intempestividad de su arribo y su carácter necesariamente revolucionario. ${ }^{25}$ Leemos en Espectros de Marx:

22 Para esta cuestión véase el debate entre Laclau y Critchley. E. Laclau, «The Time is Out of Joint», Diacritics, n II, vol. 25 (Summer 1995), pp. 86-96. S. Critchley, «Metaphysics in the Dark: A Response to Richard Rorty and Ernesto Laclau», Political Theory, n 6, vol. 26 (Dec. 1998), pp. 803-817.

23 J. Derrida, Espectros de Marx, op. cit., p. 87.

24 Ibid, p. 88.

25 En sintonía con esta interpretación de lo mesiánico, Blanchot afirma que el mesianismo judío también nos advierte sobre la relación del advenimiento con el inadvenimiento. M. 
¿Puede concebirse una herencia ateológica de lo mesiánico? [...] La ascesis despoja la esperanza mesiánica de todas las formas bíblicas e, incluso, de todas las figuras determinables de la espera, se desnuda de ese modo con vistas a responder a lo que debe ser la hospitalidad absoluta, el «sí» al (a la) arribante, el «ven» al porvenir inanticipable -que no debe ser el «cualquier cosa» detrás del cual se amparan los demasiado conocidos fantasmas que, justamente, hay que ejercitarse en reconocer. Abierta, en espera del acontecimiento como justicia, dicha hospitalidad no es absoluta más que si vela por su propia universalidad. Lo mesiánico, incluso bajo sus formas revolucionarias (y lo mesiánico siempre es revolucionario, debe serlo), sería la urgencia, la inminencia, pero, irreductible paradoja, una espera sin horizonte de espera. ${ }^{26}$

Sólo se puede esperar el porvenir, ya que sobre lo posible siempre tenemos la certeza del cálculo. Sin embargo, ese porvenir no es ajeno a nuestro aquí y ahora, ya que la propia contaminación del instante por su herencia y su porvenir hacen que el futuro nunca sea una mera repetición de lo mismo. ${ }^{27} \mathrm{~A}$ su vez, el respeto hacia la alteridad, el tomar en cuenta su singularidad de manera incondicional, es decir, la justicia, implican esta interrupción del retorno de lo mismo, para que lo otro tenga lugar. En este sentido, la deconstrucción siempre es esta llamada al porvenir desde cualquier instancia que se diga presente.

La necesaria dis-yunción, la condición des-totalizante de la justicia, es aquí la del presente y, al tiempo, la condición misma del presente y de la presencia del presente. Aquí se anunciaría siempre la deconstrucción como pensamiento del don y de la indeconstructible justicia, indeconstructible condición de toda deconstrucción, cierto, pero condición que está ella misma en deconstrucción y permanece, y debe permanecer -ésta es la inyunción- en la dis-yunción del Un-Fug. En caso contrario, descansaría en la buena conciencia del deber cumplido, perdería la oportunidad del porvenir, de la promesa o de la llamada, del deseo también (es decir, su «propia» posibilidad), de ese desierto abisal también, «desierto en el desierto», del que hablaremos más adelante, un desierto que hace señas hacia el otro, desierto abisal y caótico, si es que el caos describe antes que nada la inmensidad, la desmesura, la desproporción de una boca abierta de par en par -en la espera o en la llamada de lo que denominamos aquí, sin saber, lo

Blanchot, La escritura del desastre, tr. P. de Place. Caracas: Monte Ávila, 1990, p. 121.

26 J. Derrida, Espectros de Marx, op. cit., p. 188.

27 Gerard Bensussan interpreta lo mesiánico en Derrida, relacionándolo con algunos de los autores clásicos del mesianismo judío, desde la perspectiva del instante, entendido como aquello que rompe con el devenir de la historia e instaura una urgencia del orden práctico. G. Bensussan, «La política y el tiempo. En torno a Derrida y al mesianismo», tr. I. Dentrambasaguas, Actuel Marx, 3 (2005), pp. 77-101. 
mesiánico: la venida del otro, la singularidad absoluta e inanticipable del y de lo arribante como justicia. ${ }^{28}$

Y aquí volvemos a la crítica del comienzo del apartado. Derrida reconoce que su pensamiento contiene un peligro, que es la apertura hacia el mal y lo peor. Sin embargo, nueva aporía, esta posibilidad debe estar siempre abierta si queremos pensar en un porvenir, es decir, otra política. Todo cierre y rechazo ante la llamada del otro, previa a la conformación de cualquier mismidad, incluso en nombre del «bien», la «paz» y la «justicia», implica una violencia sobre la singularidad de ese absolutamente otro. Recurriendo a la lógica de lo autoinmunitario, si un cuerpo vivo se inmuniza contra toda posible intromisión, incluida la posibilidad de lo peor, cierra las puertas a aquello mismo que lo conforma como sí mismo: la llegada del otro. ${ }^{29}$ Asegurarse contra el riesgo de algún mal limitando la visita del otro según cumpla con las condiciones previas para su invitación ${ }^{30}$ significa también limitar el ámbito de lo posible sólo a lo meramente posible, anulando aquello que se nos impone desde un pasado inmemorial y el porvenir, lo imposible mismo, la justicia, la democracia por venir. Leemos en Fuerza de ley:

Abandonada a ella misma, la idea incalculable y donadora de justicia está siempre lo más cerca del mal, por no decir de lo peor puesto que siempre puede ser reapropiada por el cálculo más perverso. Siempre es posible y esto forma parte

28 J. Derrida, Espectros de Marx, op. cit., pp. 41-42.

29 En su intervención inmediata ante los sucesos del 11 de Septiembre de 2001, Derrida critica a la respuesta del gobierno de Bush y los Estados asociados a éste el haber presentado a sus adversarios solamente como terroristas y sobre todo como «terroristas internacionales», a los cuales se pretendió oponer una «guerra limpia». De este modo, señala que nos enfrentamos a un doble programa teológico-político, quizá más evidente por el lado islámico, pero no menor por el de los Estados Unidos, desde el momento en que se autoproclaman dogmáticamente como los garantes de la paz, la libertad y la justicia, y a partir de este fundamento planifican y llevan a cabo las acciones más terroríficas. J. Derrida, «Autoinmunidad: suicidios simbólicos y reales», en G. Borradori (ed.), La filosofía en una época de terror. Diálogos con Jürgen Habermas y Jacques Derrida, tr. J. J. Botero y L. E. Hoyos. Buenos Aires: Taurus, 2004, p. 162. Siguiendo con esta crítica, años después analiza el concepto de «Estado canalla» (rogue State), con el que se designa a todo Estado que transgrede el derecho internacional, y afirma que las acusaciones y campañas dirigidas contra los Estados así denominados (incluso cuando el adversario no es ningún Estado identificable) están orquestadas por Estados hegemónicos, empezando por los Estados Unidos, los cuales se comportan ellos mismos como Estados canallas. J. Derrida, «La razón del más fuerte (¿Hay Estados canallas?)», en Canallas: dos ensayos sobre la razón, tr. C. de Peretti. Madrid: Trotta, 2005.

30 Para un análisis de la hospitalidad de invitación (condicional) y su indisociable hospitalidad de visitación (incondicional) remitimos a J. Derrida, «Autoinmunidad: suicidios simbólicos y reales», en G. Borradori (Ed.), La filosofía en una época de terror. Diálogos con Jürgen Habermas y Jacques Derrida, op. cit., pp. 186-188. 
de la locura de la que hablábamos. Una garantía absoluta contra este riesgo sólo puede saturar o suturar la apertura de la apelación a la justicia, una apelación siempre herida. Pero la justicia incalculable ordena calcular. ${ }^{31}$

Aquí Derrida sostiene que el derecho, la política y las instituciones siguen siendo ficciones útiles, en tanto se sostenga infatigablemente un proceso deconstructivo que garantice la no caída en esencialismos y dogmatismos que acercarían a los totalitarismos políticos. ${ }^{32}$ La utilidad de dichas ficciones radicaría en esa violencia justa que se ejercería contra la posibilidad del mal. Ese momento performativo anárquico, es decir, infundado, y por lo tanto violento, evitaría así la caída en la peor de las determinaciones. ¿Cómo evitar que el porvenir sea desplazado por «cualquier cosa»? Precisamente sometiendo a lo que se proclama como la llegada del Mesías a la mirada deconstructiva. Si la soporta, es decir, si esa decisión se reconoce como infundada y llama a su propia superación, nos aseguramos un paso más en el camino infinito que conduce a la democracia por venir. Desde ya que este carácter abismal de toda decisión, su trasfondo de indecidibilidad, es precisamente el espacio en que una ética, la responsabilidad y la justicia, comprendidas todas por la misma deconstrucción, tienen lugar, aunque en ese mismo instante caigan en el orden de lo instituido. Desde allí, vislumbramos el «círculo vicioso» infinito que caracteriza a la deconstrucción, aunque desde ya que nunca se termina donde se comenzó, y aquí radica el optimismo derridiano expresado en su llamado a la perfectibilidad infinita del derecho y la democracia.

\section{INVENCIÓN}

Según lo visto hasta aquí podríamos aventurar una interpretación de la política derridiana como una política de la pasividad. Si la deconstrucción «no se aplica jamás a nada exterior», ${ }^{33}$ si siempre es una auto-hetero-deconstrucción que realiza un texto sobre sí, si nunca es una posibilidad sino siempre una invención de lo imposible, ${ }^{34}$ parece que sería suficiente con quedarse de brazos cruzados cual espectadores privilegiados de ese porvenir que ya solo se anuncia pero que de ningún modo llegará. Sin embargo, desde esta interpretación que

31 J. Derrida, Fuerza de ley. El «Fundamento místico de la autoridad», op. cit., p. 64.

32 Derrida señala que incluso sin la apertura de la posibilidad del mal puede que no quede sino la necesidad de lo peor. J. Derrida, Espectros de Marx, op. cit., p. 42.

33 J. Derrida, Fuerza de ley. El «Fundamento místico de la autoridad», op. cit., p. 81.

34 J. Derrida, «Psyche: Invenciones del otro», tr. M. Rodés de Clérico y W. Neira Blanco, en AA.VV., Diseminario: La desconstrucción, otro descubrimiento de América, Montevideo, XYZ Ediciones, 1987, pp. 49-106. 
reafirmaría a Derrida como un pensador del fin de la historia, ${ }^{35}$ sería sorprendente encontrarnos con afirmaciones como la siguiente:

Pues, lejos de que haya que renunciar al deseo emancipatorio, hay que empeñarse en él más que nunca, al parecer, como aquello que, por lo demás, es lo indestructible mismo del «es preciso». Esa es la condición de una repolitización, tal vez de otro concepto de lo político. ${ }^{36}$

Derrida llama a seguir el sueño emancipatorio y desde aquí a pensar en otra política, la democracia por venir. Si bien la deconstrucción es lo que hay, lo que acontece en las fisuras de nuestra herencia, ${ }^{37}$ es necesaria una intensificación de esto que desde siempre está en marcha. Leemos en Fuerza de ley, refiriéndose a trabajos de colegas cercanos a su pensamiento:

Me parece que responden a los programas más radicales de una deconstrucción que querría, para ser consecuente con ella misma, no quedarse encerrada en discursos puramente especulativos, teóricos y académicos sino [...] tener consecuencias, cambiar cosas, intervenir de manera eficiente y responsable (aunque siempre mediatizada evidentemente), no sólo en la profesión sino en lo que llamamos la ciudad, la pólis, y más generalmente el mundo. No cambiarlos en el sentido sin duda un poco ingenuo de realizar una intervención calculada, deliberada y estratégicamente controlada, sino en el sentido de la intensificación máxima de una transformación en curso, a título no simplemente de síntoma o de causa; aquí necesitaríamos otras categorías. ${ }^{38}$

Si bien la transformación está en curso, y no es un mero síntoma o causa de otra cosa ya que esa transformación responde al carácter autoinmunitario de todo presente, debemos radicalizar ese espíritu crítico y deconstructor. Para esto, es necesario inventar nuevos conceptos, un nuevo lenguaje, que nos permita hacer lugar al porvenir. ${ }^{39}$ Porque en última instancia una invención, si la hay, siempre es la venida del otro, que se sustrae a una programación y rompe así con todo estatuto previo. Si la invención fuera invención de lo posible, ya dejaría de ser

35 Esta lectura de Derrida lo aceraría a lo que él mismo critica encarnado en la escatología cristiano-neoliberal de Fukuyama, en J. Derrida, Espectros de Marx, op. cit., pp. 70-89.

36 J. Derrida, Espectros de Marx, op. cit., p. 89.

37 Para esta cuestión véase M. B. Cragnolini, «Derrida: deconstrucción y pensar en las "fisuras"», en Derrida, un pensador del resto, op. cit., pp. 11-23.

38 J. Derrida, Fuerza de ley. El «Fundamento místico de la autoridad», op. cit., p. 23.

39 «Tal posible no pertenecería ya al espacio de este posible, a la posibilidad de lo posible [...]. Para abrirse a esa otra posibilidad de lo posible, la misma palabra experiencia tendría que designar otro concepto. E intentar traducirse, si esa otra posibilidad fuese posible ahí, en un lenguaje político. Al precio, si eso fuera necesario, de cambiar el sentido de la palabra «político» --dicho de otro modo, cambiar la política». J. Derrida, Políticas de la amistad, seguido de El oído de Heidegger, op. cit., p. 85-86. 
tal. Para que haya invención ésta debe ser invención de lo imposible, una invención de aquello que escapa a la previsión del sujeto, al cálculo, y por eso debe venir siempre del otro. Entonces, la invención no la hacemos venir, sino que la dejamos venir preparándonos para la venida del otro. Aunque exista un efecto de subjetividad necesario e implícito en toda invención, y de aquí su inmediata incorporación a un estatuto determinado, ese efecto debe reducirse (sin limitación, negación o irresponsabilidad) a dar lugar y dejar venir al otro. ${ }^{40} \mathrm{Y}$ para que éste pueda llegar como tal, es necesario que nuestra tarea sea desobrada, ${ }^{41}$ es decir, que se esfuerce por reducir al mínimo el vínculo entre ese efecto de subjetividad necesario y la tradición del sujeto moderno. Para que otra política sea posible, debe escapar a la corta vista del sujeto y su voluntad instrumentalizadora. Hay que inventar otra política, otro lenguaje, otra subjetividad, tarea que ha encarnado el propio Derrida y que quizá sea la única posible para el filósofo-artista, filósofo del porvenir.

SEBASTIÁN CHUN pertenece al CONICET, Argentina.

\section{Publicaciones recientes:}

«Entre Blanchot y Kafka: más allá de la ley, el silencio», Revista de Filosofía, Universidad de Chile, Santiago, en prensa. ISSN 0034-8236.

«Políticas de la muerte: de la lógica soberana a la democracia por venir», A Parte Rei. Revista de Filosofía, no 67, Enero 2010, Madrid, http://serbal.pntic.mec.es/. ISSN 1137-8204.

Línea de investigación:

Actualmente se encuentra realizando el doctorado sobre la política en Jacques Derrida y su relación con la ética de Emmanuel Lévinas.

Dirección electrónica: sebaschun@hotmail.com

40 J. Derrida, «Psyche: Invenciones del otro», en AA.VV., Diseminario: La desconstrucción, otro descubrimiento de América, op.cit.

41 Para la noción de desobra véase M. Blanchot., La comunidad inconfesable, tr. I. Herrera. Madrid: Arena, 1999, pp. 35-36. 